马豪宇, 陈冠陶, 王宇, 陈蕙心, 李青桦, 涂利华.氮添加对亚热带常绿阔叶林土壤溶液化学特性的影响.生态学报, 2021,41(23):9354-9363. Ma H Y, Chen G T, Wang Y, Chen H X, Li Q H, Tu L H.Effects of nitrogen addition on soil solution chemistry in a subtropical evergreen broad-leaved forest.Acta Ecologica Sinica, 2021,41(23) : 9354-9363.

\title{
氮添加对亚热带常绿阔叶林土壤溶液化学特性的影响
}

\author{
马豪宇 ${ }^{1,2,3}$ ，陈冠陶 $1,2,4$ ，王 宇 ${ }^{1,2}$ ，陈萬心 ${ }^{1,2}$ ，李青桦 ${ }^{1,2}$, 涂利华 ${ }^{1,2}$ * \\ 1 四川农业大学林学院, 长江上游森林资源保育与生态安全国家林业和草原局重点实验室, 成都 611130 \\ 2 四川农业大学林学院, 长江上游林业生态工程四川省重点实验室, 成都 611130 \\ 3 太原市林业科学研究所,太原 030000 \\ 4 德国哥廷根大学,森林科学和森林生态学院, 热带和亚热带生态系统土壤学系, 德国哥廷根 37077
}

\begin{abstract}
摘要:土壤溶液被称作“土壤的血液”, 是土壤中各种生物化学反应的中介物质,在外界环境发生变化时,土壤溶液化学成分能 在其他土壤指标尚无变化之前对环境变化做出迅速响应。为了探索持续增加的大气氮 $(\mathrm{N})$ 沉降对森林生态系统的影响, 以华 西雨屏区亚热带常绿阔叶林为对象, 设置对照 $\left(\mathrm{CK}, 0 \mathrm{~g} \mathrm{~m}^{-2} \mathrm{a}^{-1}\right)$, 低 $\mathrm{N}\left(\mathrm{LN}, 5 \mathrm{~g} \mathrm{~m}^{-2} \mathrm{a}^{-1}\right)$, 高 $\mathrm{N}\left(\mathrm{HN}, 15 \mathrm{~g} \mathrm{~m}^{-2} \mathrm{a}^{-1}\right)$ 三种 $\mathrm{N}$ 处理, 通 过人工施加硝酸铵 (2017 年 9 月起改施硝酸钠及氯化铵) 的方法模拟 $\mathrm{N}$ 沉降增加情景, $\mathrm{N}$ 处理 42 个月后, 使用负压土壤溶液采 样器定位收集 A 层 $(37-45 \mathrm{~cm})$ 及 B 层 $(52-60 \mathrm{~cm})$ 土壤溶液,并进行分析(每月 1 次, 为期 $1 \mathrm{a})$ 。结果表明: 对照处理中 A、B 两层土壤溶液 $\mathrm{NO}_{3}^{-}$浓度达 $(3.94 \pm 0.77) \mathrm{mg} / \mathrm{L} 、(4.27 \pm 1.13) \mathrm{mg} / \mathrm{L}, \mathrm{N}$ 添加显著提高两层土壤溶液 $\mathrm{NO}_{3}^{-}$浓度和 $\mathrm{B}$ 层 $\mathrm{NH}_{4}^{+}$浓度; $\mathrm{N}$ 添加显著降低土壤溶液 $\mathrm{pH}$, 且显著增加 $\mathrm{Al}^{3+}$ 浓度, $\mathrm{Ca}^{2+}$ 和 $\mathrm{Mg}^{2+}$ 含量有增加趋势, 但影响不显著; $\mathrm{N}$ 处理使 $\mathrm{A}$ 层土壤溶液可溶性 有机碳 $(\mathrm{DOC})$ 浓度显著降低, 对两层土壤溶液芳香化指数 $(\mathrm{AI})$ 无显著影响; 两层土壤溶液电导率 $(\mathrm{EC})$ 及氧化还原电位 $(\mathrm{Eh})$ 显 著增加; 此外, 两层土壤溶液中许多化学成分均呈现极显著相关, 特别是 $\mathrm{NO}_{3}^{-}$与 $\mathrm{EC}$ 相关系数达到了 0.855 。本研究中, 对照处 理极高的 $\mathrm{NO}_{3}^{-}$含量以及 $\mathrm{B}$ 层土壤溶液硝酸盐浓度高于 $\mathrm{A}$ 层, 表明该亚热带常绿阔叶林 $\mathrm{N}$ 的有效性超过植物和微生物的总营养 需求而发生淋溶, 该生态系统已达到氮饱和状态, 此外 $\mathrm{N}$ 添加会显著促进土壤酸化和铝离子活化, 表层土壤溶液 DOC 的降低一 定程度反映了调落物分解受 $\mathrm{N}$ 添加的抑制作用,显著升高的氧化还原电位可能导致土壤中某些金属元素的迁移率降低。
\end{abstract}

关键词:氮添加;常绿阔叶林;土壤溶液;化学成分;氮饱和

\section{Effects of nitrogen addition on soil solution chemistry in a subtropical evergreen broad-leaved forest}

\footnotetext{
MA Haoyu ${ }^{1,2,3}$, CHEN Guantao ${ }^{1,2,4}$, WANG Yu ${ }^{1,2}$, CHEN Huixin ${ }^{1,2}$, LI Qinghua ${ }^{1,2}$, TU Lihua ${ }^{1,2, *}$

1 National Forestry and Grassland Administration Key Laboratory of Forest Resources Conservation and Ecological Safety on the Upper Reaches of the Yangtze River, College of Forestry, Sichuan Agricultural University, Chengdu 611130, China

2 Sichuan Province Key Laboratory of Ecological Forestry Engineering on the Upper Reaches of the Yangtze River, College of Forestry, Sichuan Agricultural University, Chengdu 611130, China

3 Taiyuan Institute of Forestry Sciences, Taiyuan 030000 , China

4 Soil Science of Tropical and Subtropical Ecosystems, Faculty of Forest Sciences and Forest Ecology, University of Goettingen, Goettingen 37077, Germany
}

\begin{abstract}
Soil solution is called "soil blood", which is the medium of various biochemical reactions in the soil. When the external environment changes, the chemical composition of the soil solution can quickly respond to the environmental changes before other soil indicators have changed. In order to explore the impact of increasing atmospheric nitrogen ( $\mathrm{N}$ )

基金项目:国家自然科学基金项目 (32071591); 国家级大学生创新性实验计划项目 (201910626003,202010626023); 四川省教育厅项目 (17ZA0310)
\end{abstract}

收稿日期:2020-10-21; 网络出版日期:2021-07-25

*通讯作者 Corresponding author.E-mail: tulhsicau@163.com 
deposition on forest ecosystems, we set up three $\mathrm{N}$ treatments including the control ( $\mathrm{CK}, 0 \mathrm{~g} \mathrm{~m}^{-2} \mathrm{a}^{-1}$ ), low $\mathrm{N}$ ( $\mathrm{LN}, 5 \mathrm{~g}$ $\left.\mathrm{m}^{-2} \mathrm{a}^{-1}\right)$, and high $\mathrm{N}\left(\mathrm{HN}, 15 \mathrm{~g} \mathrm{~m}^{-2} \mathrm{a}^{-1}\right)$ in a subtropical evergreen broad-leaved forest in the raining area of west China, artificially applied ammonium nitrate to simulate the increase of $\mathrm{N}$ deposition (replaced with sodium nitrate and ammonium chloride since September 2017). After 42 months of N treatment, soil solution from two soil layers (layer A: $37-45 \mathrm{~cm}$, layer B : 52-60 cm) was collected using negative pressure soil solution sampler and analyzed chemical composition once a month for a year. In CK, soil solution $\mathrm{NO}_{3}^{-}$concentration reached $(3.94 \pm 0.77) \mathrm{mg} / \mathrm{L}$ (layer A) and $(4.27 \pm 1.13) \mathrm{mg} / \mathrm{L}$ ( layer B). Nitrogen additions significantly increased soil solution $\mathrm{NO}_{3}^{-}$and $\mathrm{NH}_{4}^{+}$concentration in layer B. Nitrogen additions significantly reduced soil solution $\mathrm{pH}$ value and increased $\mathrm{Al}^{3+}$ concentration, and the concent of $\mathrm{Ca}^{2+}$ and $\mathrm{Mg}^{2+}$ increased with no significant in statistics. Nitrogen treatment significantly reduced the dissolved organic carbon (DOC) concentration in layer A, and had no significant effect on the aromatic index (AI) of soil solution in the two layers. The electrical conductivity (EC) and the redox potential (Eh) of soil solution increased significantly in two soil layers. In addition, many chemical components in the soil solution of two layers had extremely significant correlation, especially the correlation

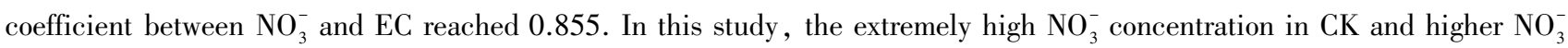
concentration in layer B than in layer A indicated that the nitrogen availability of the subtropical evergreen broad-leaved forest exceeded the total nutrient requirements of plants and microorganisms, and the ecosystem had reached the state of nitrogen saturation. In addition, nitrogen addition significantly promoted soil acidification and aluminum activation. The decrease of DOC in surface soil solution to some extent reflected the inhibition of litter decomposition by nitrogen addition. The significant increase of redox potential may lead to the decrease of the mobility of some metal elements in the soil.

Key Words : nitrogen addition; evergreen broad-leaved forest; soil solution; chemical component; nitrogen saturation

因矿石燃料的燃烧、肥料的使用等人为活动的骤增, 向大气排放的活性氮 $(\mathrm{N})$ 以及从大气沉降的 $\mathrm{N}$ 日益 增加, $\mathrm{N}$ 沉降目前已成为全球三大变化问题之一 ${ }^{[1]}$ 。据估计, 工业革命前因人为活动产生的 $\mathrm{N}$ 沉降量仅为目 前的十一分之一 ${ }^{[2-3]}$, 且未来仍将持续增加。中国 $\mathrm{N}$ 沉降量在过去 30 年增幅达 $60 \%{ }^{[4]}$ 。森林是 $\mathrm{N}$ 沉降的主 要承受者, $\mathrm{N}$ 沉降的增加对森林生态系统产生了深远的影响 ${ }^{[5]}$, 因此探究 $\mathrm{N}$ 沉降对该生态系统的影响及其机 制十分重要。

土壤溶液化学成分是森林生物化学变化中的敏感指标, 对 $N$ 输人等环境变化响应迅速 ${ }^{[6]}$, 为研究 $N$ 沉降 对森林生态系统的影响提供了另一种研究方向。同时,土壤形成过程及土壤中的生物化学反应大多以土壤溶 液为发生场所, 因此, 土壤溶液化学成分的变化能够一定程度反映土壤的最新状态 ${ }^{[7]}$ 。对于植物而言, 相比 土壤中较高的养分含量, 土壤溶液中的养分含量能更好反映土壤养分的供给情况 ${ }^{[8]}$ 。人们通过分析土壤溶 液化学成分的变化, 可掌握土壤中各种生物化学反应的过程、作用机理及其与所处环境的关系。因此, 研究土 壤溶液的化学成分动态变化将有助于深人认识 $N$ 沉降对森林生态系统的影响及其机制。

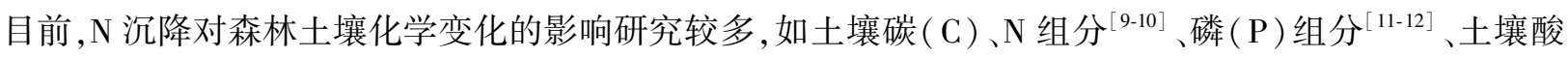
化 ${ }^{[13-14]}$ 、土壤酶活性 ${ }^{[15-16]}$ 、土壤呼吸 ${ }^{[17]}$ 等, 而 $\mathrm{N}$ 沉降对土壤溶液化学成分影响的研究较少, 且大多数以离心 法或者水/盐溶液提取法采集土壤溶液样品 ${ }^{[7,18]}$, 无法获得长期定位研究数据。同时,这些方法会破坏土壤 结构, 从而影响溶液中一些化学成分的浓度, 因此不能清楚反映自然状态中 $\mathrm{N}$ 沉降对森林土壤溶液的影响。

土壤储存的 $\mathrm{N}$ 库是整个森林生态系统 $\mathrm{N}$ 库的主体。植物在土壤中主要以 $\mathrm{NH}_{4}^{+}-\mathrm{N}$ 和 $\mathrm{NO}_{3}^{-}-\mathrm{N}$ 的形式来吸 收 $\mathrm{N}$, 因此土壤有效 $\mathrm{N}$ 的主要形式是 $\mathrm{NH}_{4}^{+}$和 $\mathrm{NO}_{3}^{-}$。 $\mathrm{N}$ 沉降能够直接影响土壤以及土壤溶液 $\mathrm{N}^{\text {素浓度 }}{ }^{[19]}$, 土 壤中无机 $\mathrm{N}$ 的增加可能会使土壤盐基阳离子 $\left(\mathrm{Ca}^{2+}, \mathrm{Mg}^{2+}, \mathrm{K}^{+}, \mathrm{Na}^{+}\right)$及酸性离子 $\mathrm{H}^{+} 、 \mathrm{Al}^{3+}$ 等释放至土壤溶 液 $^{[20-21]}$, 即引起土壤溶液酸化、重金属离子活化等一系列反应,进而改变土壤养分、植物生长、地下水质量等。 可溶性有机碳 (DOC) 是土壤的重要 $\mathrm{C}$ 库, 不仅能够为植物提供养分, 又是土壤微生物分解的底物, 也是重要 的载体及有机配体, 可显著影响土壤及土壤溶液中一些化学成分的吸附、解吸等转化过程 ${ }^{[22-23]}$, DOC 的产生 与分解过程受调落物分解、微生物活性、土壤呼吸、植物吸收等多方面影响, 国内外目前关于土壤溶液 DOC 受 $\mathrm{N}$ 添加影响的研究结果有增加 ${ }^{[23]}$ 、减少 ${ }^{[24]}$ 及不变 ${ }^{[25]}$ 三种, 仍存在较大争议。另外, 土壤溶液中有不少氧化还 
原体系,如铁体系、锰体系等,它们决定着土壤溶液的氧化还原性质,从而影响土壤溶液中金属离子的迁移、养 分的有效性、物质的转化等 ${ }^{[26]}$ 。

由于特殊的地理区位和地形, “华西雨屏”的年平均降水量在 1500 至 $2000 \mathrm{~mm}$ 之间,湿 $\mathrm{N}$ 沉降量约为 $95 \mathrm{~kg} \mathrm{hm}^{-2} \mathrm{a}^{-1}$, 处于很高水平 ${ }^{[27]}$ 。长期的、高量的背景 $\mathrm{N}$ 沉降量的累积, 极易造成生态系统 $\mathrm{N}$ 素过量, 从而 达到 N 饱和状态。课题组于 2013 年在 “华西雨屏” 中心地带碧峰峡亚热带常绿阔叶林中建立了长期 $N$ 添加 固定样地, 前期发现 $\mathrm{N}$ 添加显著降低了表层土壤的 $\mathrm{pH}$, 抑制了土壤呼吸速率, 增加了土壤有机碳含量, 并且 土壤 $\mathrm{N}$ 素含量很高 ${ }^{[17,28-29]}$ 。基于前期结果, 在已进行 $\mathrm{N}$ 添加处理 42 个月的样地上使用负压土壤溶液采样器 定位采集不同深度土壤溶液,并分析化学成分。通过该生态系统的硝态氮淋溶情况判断生态系统是否已达 $\mathrm{N}$ 饱和状态, 并探索高背景 $\mathrm{N}$ 沉降下, 持续增加的大气 $\mathrm{N}$ 沉降对土壤溶液化学特性的影响, 并为预测大气 $\mathrm{N}$ 沉 降持续增加对该区域森林生态变化提供理论依据和数据支撑。

\section{1 材料与方法}

\section{1 研究区概况}

研究区 ${ }^{[30]}$ 位于 “华西雨屏区” 中心地带的四川雅安碧峰峡自然保护区 $\left(103^{\circ} 00^{\prime} \mathrm{E}, 30^{\circ} 04^{\prime} \mathrm{N}\right)$, 所属气候为 亚热带湿润季风气候, 年均温 $16.2^{\circ} \mathrm{C}$, 年日照长度 $1040 \mathrm{~h}$, 年蒸发量 $1011 \mathrm{~mm}$, 年均降水量 $1772 \mathrm{~mm}$, 年平均相 对湿度 79\%。试验地为该保护区中山段的千家山林班, 林班较为平坦, 绝大部分坡度 $<5^{\circ}$, 海拔约 $1026 \mathrm{~m}$, 林 分类型为常绿阔叶次生林, 土壤类型为山地黄壤, 调落物层厚约 $5 \mathrm{~cm}$, 土表腐殖质层厚度大约 $10 \mathrm{~cm}$, 总土壤 深度一般大于 $60 \mathrm{~cm}$ 。样地主要树种有木荷 (Schima superba)、红淡比 (Cleyera japonica)、木姜子 ( Litsea cubeba) 等。详细树种组成和土壤基本理化性质见文献 ${ }^{[16]}$ 。

\section{2 样地设置与 $\mathrm{N}$ 添加处理}

2013 年 11 月, 在试验地布设 12 块 $20 \mathrm{~m} \times 20 \mathrm{~m}$ 的样地, 样地间距 $>20 \mathrm{~m}$, 所有样地相互间的距离均在 1 $\mathrm{km}$ 以内。共设三个处理: 对照、低氮和高氮, 氮添加量分别为 $0 、 5 、 15 \mathrm{~g} \mathrm{~N} \mathrm{~m}^{-2} \mathrm{a}^{-1}$, 由于样地背景氮沉降量约为 $10 \mathrm{~g} \mathrm{~N} \mathrm{~m}^{-2} \mathrm{a}^{-1}$, 所以低氮和高氮处理模拟氮沉降增加 50\% 和 $150 \%$ 的情景, 12 个样地随机分配于 3 个处理, 每 个处理 4 个重复样地。具体的施氮方法是: 首先将年 $N$ 添加量等分为 12 份, 然后每个月将等量的硝酸铵 $\left(\mathrm{NH}_{4} \mathrm{NO}_{3}\right)$ 溶解于水喷洒至样地地表,2014 年 1 月开始第一次施氮。后由于 $\mathrm{NH}_{4} \mathrm{NO}_{3}$ 大量停产而无法购置, 从 2017 年 9 月起,利用 $\mathrm{NaNO}_{3}$ 及 $\mathrm{NH}_{4} \mathrm{Cl}$ 进行定量施氮。每次施氮时将各样地所需 $\mathrm{N}$ 添加量溶于 $10 \mathrm{~L}$ 水中, 在 该样地中用喷雾器均匀喷酒, CK 喷酒 10L 清水。

\section{3 样品采集与处理}

于 2016 年 12 月和 2017 年 4 月,分别在每块样地的 $60 \mathrm{~cm}$ 和 $45 \mathrm{~cm}$ 布设陶瓷头土壤溶液取样管( S32 型, 众添公司, 中国)。土壤溶液取样管的陶土头, 即用于采集土壤溶液的有效部分长度为 $8 \mathrm{~cm}$, 因此, 试验采集 到的土壤溶液为 $\mathrm{A}$ 层 $(37-45 \mathrm{~cm})$ 和 $\mathrm{B}$ 层 $(52-60 \mathrm{~cm})$ 的样品。为减少前期土壤扰动对土壤溶液造成的影 响, 布设土壤溶液取样管后的前几个月不采样。2017 年 7 月到 2018 年 6 月,每月施 $\mathrm{N}$ 前, 用负压法采集土壤 溶液样品, 放置在 $4^{\circ} \mathrm{C}$ 泡沫箱尽快带回实验室。

采回的样品在室温下立刻测定 $\mathrm{pH}$ 、电导率 (EC)、氧化还原电位 ( $\mathrm{Eh}$ ), 随后将样品分为两份, 一份样品加 浓硝酸保存, 以测定金属离子; 另一份样品加甲苯保存, 以测定 $\mathrm{NH}_{4}^{+} 、 \mathrm{NO}_{3}^{-} 、 \mathrm{NO}_{2}^{-} 、 \mathrm{PO}_{4}^{2-} 、 \mathrm{DOC}$ 、芳香化指数 $(\mathrm{AI})$ 。 两份样品冷藏于 $4^{\circ} \mathrm{C}$ 冰箱,尽快测定各化学指标。

$\mathrm{pH}$ 的测定采用电位法; 使用电导仪 (DDS-11A 型, 上海越平科学仪器有限公司, 中国上海) 测定 $\mathrm{EC}$; 采用 电位法测定 $\mathrm{Eh}$; 使用全自动间断化学分析仪 (Smartchem 200,AMSAliance, 意大利) 测定 $\mathrm{NH}_{4}^{+} 、 \mathrm{NO}_{3}^{-} 、 \mathrm{NO}_{2}^{-} 、 \mathrm{Cr}^{6+}$; 样品经过 $0.45 \mu \mathrm{m}$ 滤膜过滤后, 使用总有机碳分析仪 (vario TOC 型, 大昌华嘉商业有限公司, 中国上海) 测定 DOC; 使用原子吸收光谱仪 (NovAA400P, 耶拿分析仪器股份公司, 德国) 测定 $\mathrm{Ca}^{2+} 、 \mathrm{Mg}^{2+} 、 \mathrm{Mn}^{2+} 、 \mathrm{Cu}^{2+} ; \mathrm{Al}^{3+}$ 的测 定采用铝试剂比色法 ( LY/T 1275-1999) ; 采用钼锑抗比色法 ( LY/T 1275-1999) 测定 $\mathrm{PO}_{4}^{2-}$; 使用紫外分光光 
度计(UV-1800 型, 美谱达仪器有限公司, 中国上海) 测定样品在 $254 \mathrm{~nm}$ 的吸光值后, 通过计算得出 AI 值: AI $=100 \times \mathrm{UV}_{254} / C(\mathrm{DOC})^{[31]}$, 式中 $\mathrm{UV}_{254}$ 为样品在 $254 \mathrm{~nm}$ 的吸光值, $C(\mathrm{DOC})$ 为 $\mathrm{DOC}$ 浓度 (单位为 $\left.\mathrm{mg} / \mathrm{L}\right) 。$

1.4 数据处理与统计分析

使用 Excel 2010 整理试验数据,使用 SPSS 20.0 统计分析试验数据。用多重比较法和重复观测方差分析 比较 $\mathrm{N}$ 添加对土壤溶液各化学指标的影响。用 Pearson 相关性分析进行土壤溶液各化学指标的相关分析。 统计学显著水平为 $\alpha=0.05$ 。使用 SigmaPlot 12.5 进行作图。

\section{2 结果与分析}

$2.1 \mathrm{~N}$ 添加对土壤溶液 $\mathrm{NH}_{4}^{+} 、 \mathrm{NO}_{3}^{-}$的影响

$\mathrm{CK}$ 下, $\mathrm{A}$ 层 $\mathrm{NH}_{4}^{+}$的年均浓度是 $(0.10 \pm 0.02) \mathrm{mg} / \mathrm{L}, \mathrm{LN}$ 和 $\mathrm{HN}$ 分别是 $\mathrm{CK}$ 的 1.5 倍和 11.5 倍; $\mathrm{CK}$ 下, $\mathrm{B}$ 层 $\mathrm{NH}_{4}^{+}$的年均浓度是 $(0.05 \pm 0.01) \mathrm{mg} / \mathrm{L}, \mathrm{LN}$ 和 $\mathrm{HN}$ 分别是 $\mathrm{CK}$ 的 1.2 倍和 5.6 倍 (图 1)。

结果表明, $\mathrm{NO}_{3}^{-}$浓度随 $\mathrm{N}$ 添加量的增加而显著增加。 $\mathrm{A}$ 层的 $\mathrm{LN}$ 和 $\mathrm{HN}$ 处理下的 $\mathrm{NO}_{3}^{-}$浓度分别是 $\mathrm{CK}$ $((3.94 \pm 0.77) \mathrm{mg} / \mathrm{L})$ 的 3.5 倍和 7.9 倍; $\mathrm{B}$ 层的 $\mathrm{LN}$ 和 $\mathrm{HN}$ 处理下的 $\mathrm{NO}_{3}^{-}$浓度分别是 $\mathrm{CK}((4.27 \pm 1.13) \mathrm{mg} / \mathrm{L})$ 的 2.7 倍和 7.3 倍(图 1)。

此外,在同一处理中,每一土层土壤溶液的 $\mathrm{NO}_{3}^{-}$浓度均显著高于 $\mathrm{NH}_{4}^{+}$浓度。

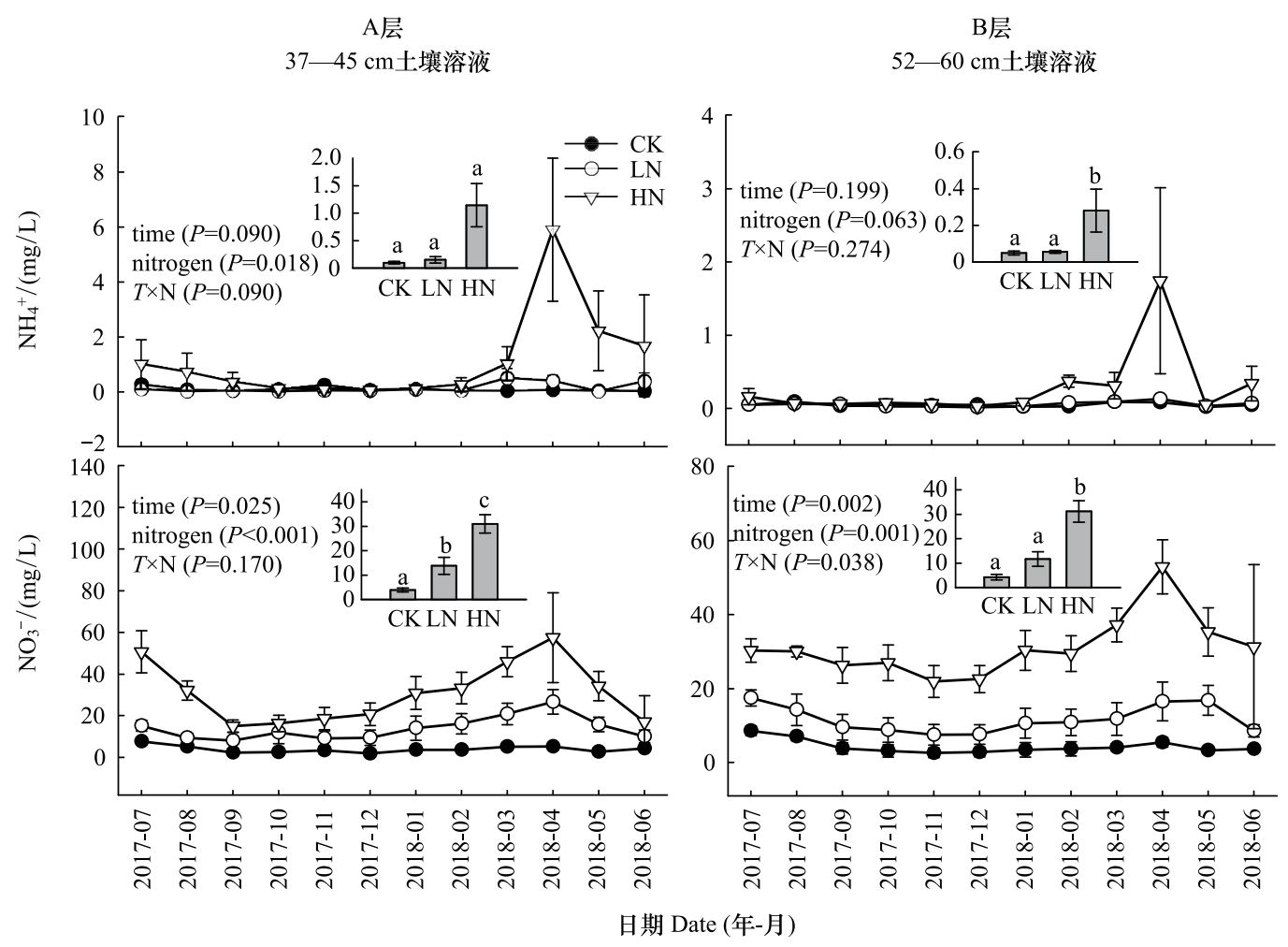

图 $1 \mathrm{~N}$ 添加对土壤溶液 $\mathrm{NH}_{4}^{+}$和 $\mathrm{NO}_{3}^{-}$的影响

Fig.1 Effects of simulated nitrogen deposition on $\mathrm{NH}_{4}^{+}$and $\mathrm{NO}_{3}^{-}$in soil solutions

CK : 对照; LN : 低 N;HN : 高 N; time: 时间效应; nitrogen: $N$ 处理效应; $\mathrm{T} \times \mathrm{N}$ : 时间与 $\mathrm{N}$ 处理交互效应 time: Effect of time; nitrogen: Effect of nitrogen; T $\times \mathrm{N}$ : Interactive effect of time and nitrogen; 图中数据为平均值 \pm 标准差; 不同小写字母代表不同 $\mathrm{N}$ 处理间差异显著

\section{$2.2 \mathrm{~N}$ 添加对土壤酸碱平衡的影响}

由于测试仪器问题, 前 8 次的 $\mathrm{pH}$ 数据未能使用。与 $\mathrm{CK}$ 比较, $\mathrm{LN}$ 处理的 $\mathrm{A} 、 \mathrm{~B}$ 层土壤溶液 $\mathrm{pH}$ 值分别降 低 0.18 和 $0.06 ; \mathrm{HN}$ 处理的 $\mathrm{A} 、 \mathrm{~B}$ 层土壤溶液 $\mathrm{pH}$ 值分别降低 1.03 和 0.75 (图 2), 两层土壤溶液均表现为深度 越深, $\mathrm{pH}$ 值降低越少, 表明土层越深, 土壤酸化的程度逐渐减弱。 
$\mathrm{LN}$ 处理对 $\mathrm{Al}^{3+}$ 浓度影响不显著, $\mathrm{HN}$ 处理使 $\mathrm{A} 、 \mathrm{~B}$ 层 $\mathrm{Al}^{3+}$ 浓度显著增加了 3.1 倍和 2.3 倍(图 2)。

在同一 $\mathrm{N}$ 添加处理水平下土壤溶液 $\mathrm{Ca}^{2+}$ 浓度随土壤深度的增加而降低, 表现为 $\mathrm{A}$ 层 $>\mathrm{B}$ 层 (图 2)。 $\mathrm{CK}$ 的 $\mathrm{Ca}^{2+}$ 年均浓度为 $(45.0 \pm 5.20) \mathrm{mg} / \mathrm{L}$ ( A 层 $)$ 和 $(40.7 \pm 3.10) \mathrm{mg} / \mathrm{L}$ ( B 层 $), \mathrm{Mg}^{2+}$ 年均浓度为 $(1.41 \pm 0.22) \mathrm{mg} / \mathrm{L}$ ( $\mathrm{A}$ 层) 和 $(1.38 \pm 0.27) \mathrm{mg} / \mathrm{L}$ (B 层), 随着 $\mathrm{N}$ 添加量的增加, $\mathrm{Ca}^{2+} 、 \mathrm{Mg}^{2+}$ 浓度有增加的趋势 ( 图 2)。

$\mathrm{A}$ 层
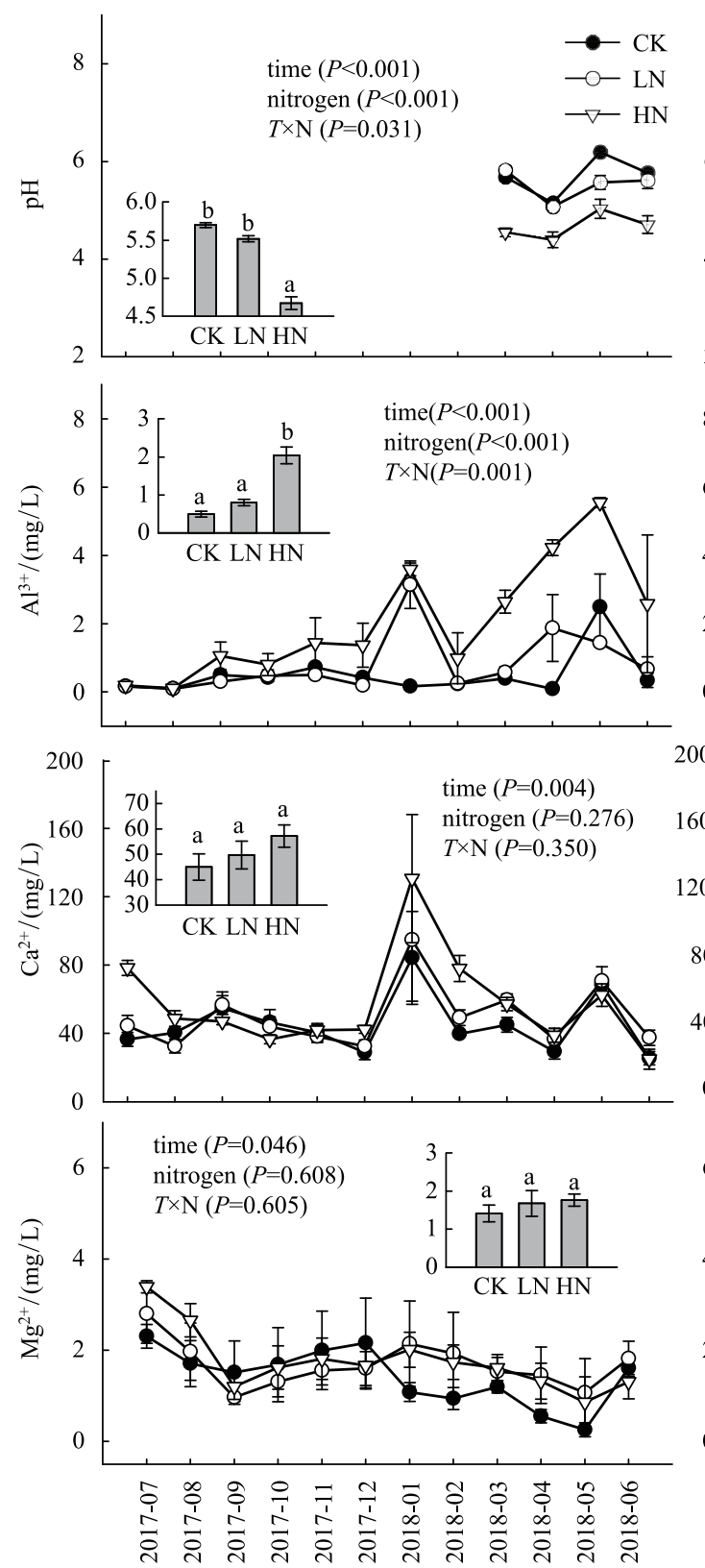

$\mathrm{B}$ 层
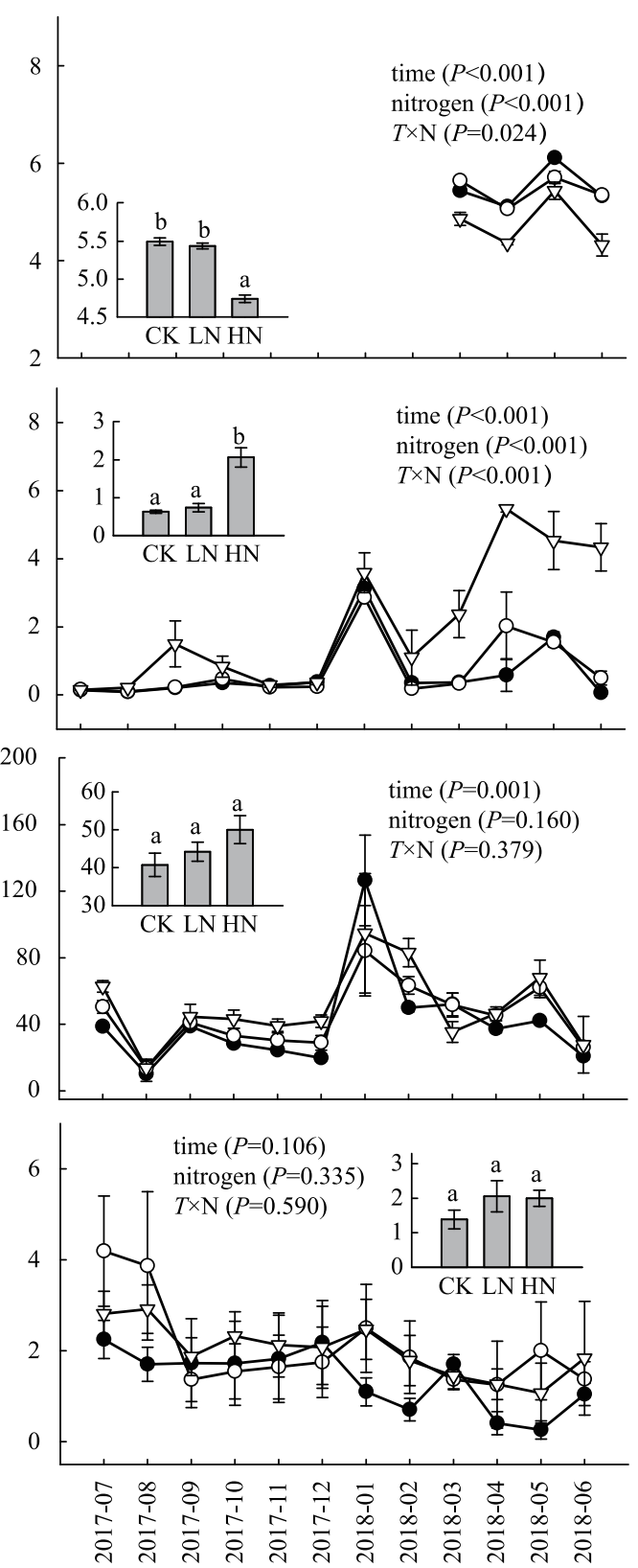

日期 Date (年-月)

图 $2 \mathrm{~N}$ 添加对土壤溶液 $\mathrm{pH} 、 \mathrm{Al}^{3+} 、 \mathrm{Ca}^{2+}$ 和 $\mathrm{Mg}^{2+}$ 的影响

Fig.2 Effects of simulated nitrogen deposition on $\mathrm{pH} \mathrm{Al}^{3+}, \mathrm{Ca}^{2+}$ and $\mathrm{Mg}^{2+}$ in soil solutions

\section{$2.3 \mathrm{~N}$ 添加对土壤溶液有机碳的影响}

$\mathrm{CK}$ 的 DOC 年均浓度为 $(12.7 \pm 0.34) \mathrm{mg} / \mathrm{L}$ ( A 层) 、 $(10.9 \pm 0.11) \mathrm{mg} / \mathrm{L}(\mathrm{B}$ 层 $), \mathrm{N}$ 添加显著抑制 $\mathrm{A}$ 层 DOC 浓度,且 LN 及 HN 均降低 20\%；B 层 DOC 浓度受 N 添加影响不显著(图 3)。

$\mathrm{CK}$ 的土壤溶液 $\mathrm{AI}$ 值为 $(1.59 \pm 0.12) \mathrm{L} \mathrm{mg}^{-1} \mathrm{~cm}^{-1}$ ( $\mathrm{A}$ 层) 和 $(1.99 \pm 0.05) \mathrm{L} \mathrm{mg}^{-1} \mathrm{~cm}^{-1}$ ( B 层), $\mathrm{N}$ 添加处理对 
AI 影响不显著( 图 3)。

$\mathrm{A}$ 层

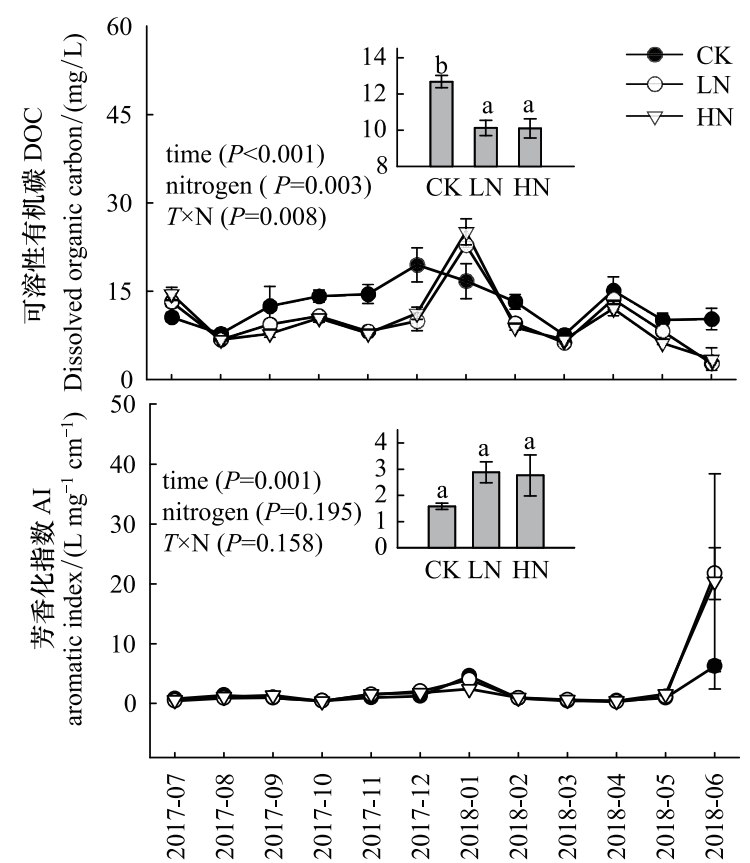

$\mathrm{B}$ 层

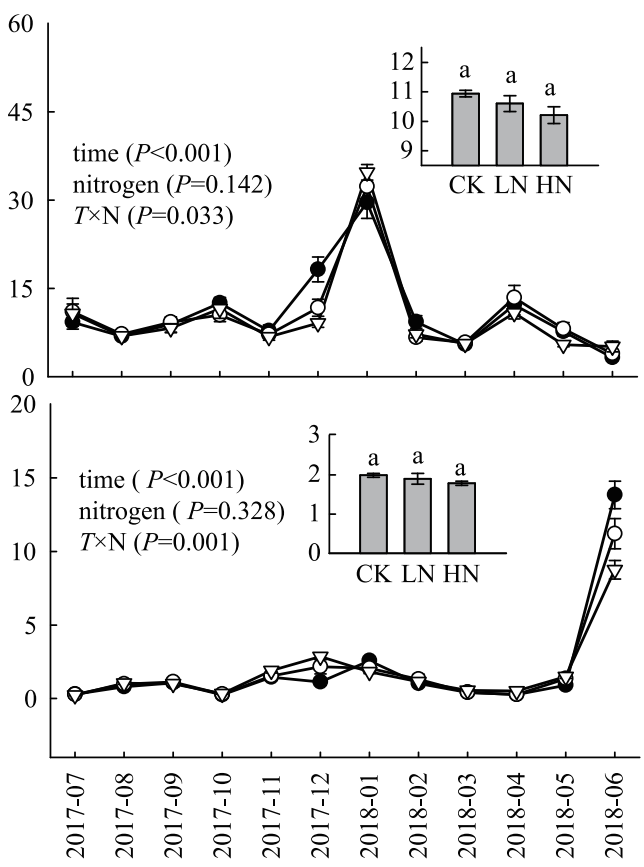

日期Date (年-月)

图 $3 \mathrm{~N}$ 添加对土壤溶液 DOC 和 AI 的影响

Fig.3 Effects of simulated nitrogen deposition on dissolved organic carbon and aromatic index in soil solutions

$2.4 \mathrm{~N}$ 添加对土壤溶液 $\mathrm{EC} 、 \mathrm{Eh}$ 的影响

同一 $\mathrm{N}$ 添加处理下, 随着土壤深度的加深, EC 降低、Eh 升高 (图 4)。

$\mathrm{A}$ 层
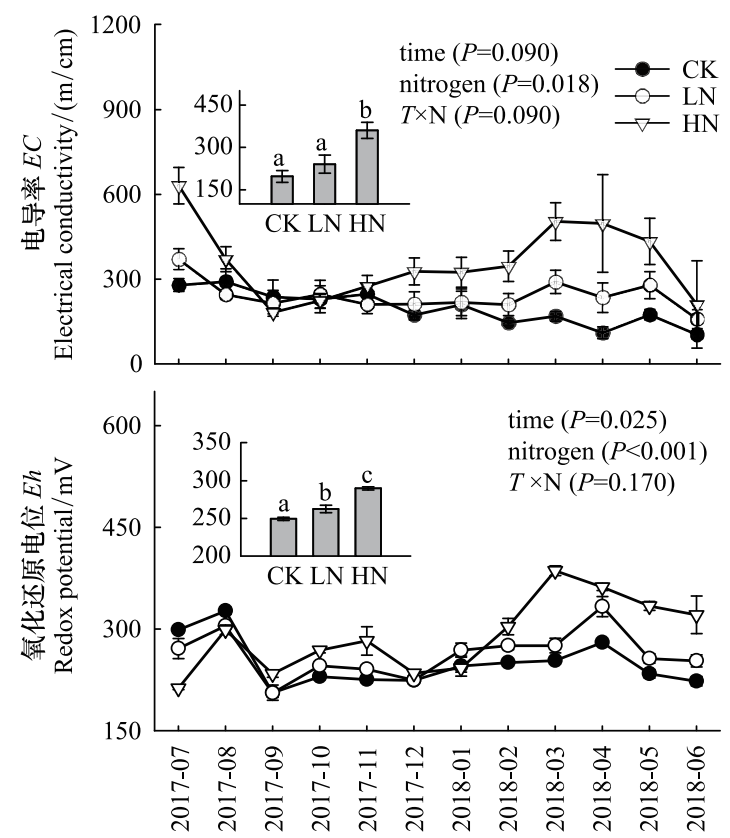

$\mathrm{B}$ 层
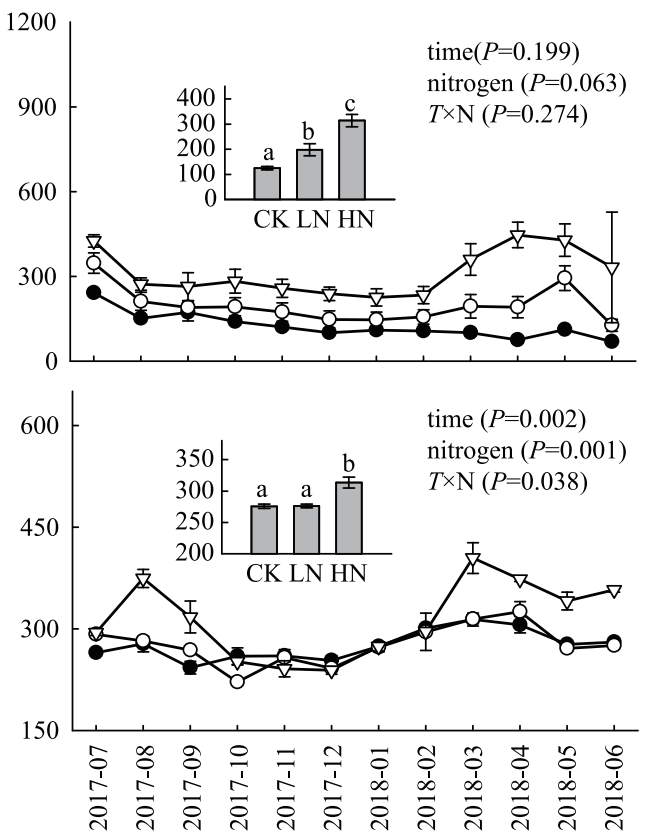

日期 Date (年-月)

图 $4 \mathrm{~N}$ 添加对土壤溶液 $\mathrm{EC}$ 和 $\mathrm{Eh}$ 的影响

Fig.4 Effects of simulated nitrogen deposition on EC and Eh in soil solutions 
CK 下, A 层的土壤溶液 EC 为 $(198 \pm 20.70) \mu \mathrm{m} / \mathrm{cm}, \mathrm{LN}$ 和 HN 处理较 CK 显著增加 $20 \%$ 和 $80 \%$; CK 下, B 层的土壤溶液 $\mathrm{EC}$ 为 $(126 \pm 6.81) \mu \mathrm{m} / \mathrm{cm}, \mathrm{LN}$ 与 $\mathrm{HN}$ 处理较 $\mathrm{CK}$ 分别增加 $60 \%$ 和 $150 \%$ (图 4)。

$\mathrm{CK}$ 的 $\mathrm{A}$ 层土壤溶液 $\mathrm{Eh}$ 为 $(249 \pm 2.2) \mathrm{mV}, \mathrm{LN}$ 与 $\mathrm{HN}$ 的 $\mathrm{Eh}$ 较 $\mathrm{CK}$ 分别增加 $5 \%$ 和 $17 \%$; $\mathrm{HN}$ 显著提高 $\mathrm{B}$ 层 土壤溶液 $\mathrm{Eh}$, 增幅达 $14 \%$ 。

$2.5 \mathrm{~N}$ 添加对土壤溶液其他化学成分的影响

土壤溶液的 $\mathrm{Mn}^{2+} 、 \mathrm{Cu}^{2+} 、 \mathrm{PO}_{4}^{2-} 、 \mathrm{Cr}^{6+} 、 \mathrm{NO}_{2}^{-}$浓度测定结果均未达到测量的最低水平,说明该生态系统土壤溶 液中的这些化学成分含量极低。

2.6 土壤溶液各化学成分的相关分析

结果表明, 土壤溶液指标间呈极显著相关, 如 $\mathrm{NH}_{4}^{+} 、 \mathrm{Al}^{3+} 、 \mathrm{Ca}^{2+} 、 \mathrm{Mg}^{2+}$ 与 $\mathrm{NO}_{3}^{-}$呈极显著正相关; $\mathrm{EC}^{\text {与 }} \mathrm{Mg}^{2+}$ 、 $\mathrm{Al}^{3+} 、 \mathrm{NH}_{4}^{+} 、 \mathrm{NO}_{3}^{-}$等呈显著正相关,特别是与 $\mathrm{NO}_{3}^{-}$的相关系数达 0.855 (表 1 ,表 2), 表明土壤溶液化学成分间相 互影响。

表 1 A 层土壤溶液各指标 Person 相关分析 $r$ 值

Table 1 Person correlation Analysis of Various Indicators in soil solution of layer A

\begin{tabular}{|c|c|c|c|c|c|c|c|c|c|}
\hline $\begin{array}{l}\text { 指标 } \\
\text { Indicators }\end{array}$ & $\mathrm{NH}_{4}^{+}$ & $\mathrm{NO}_{3}^{-}$ & $\mathrm{pH}$ & $\mathrm{Al}^{3+}$ & $\mathrm{Ca}^{2+}$ & $\mathrm{Mg}^{2+}$ & DOC & AI & $\mathrm{EC}$ \\
\hline $\mathrm{NO}_{3}^{-}$ & $0.691^{\text {** }}$ & & & & & & & & \\
\hline $\mathrm{pH}$ & -0.379 & -0.345 & & & & & & & \\
\hline $\mathrm{Al}^{3+}$ & $0.471^{\text {** }}$ & $0.490^{* *}$ & -0.572 & & & & & & \\
\hline $\mathrm{Ca}^{2+}$ & 0.004 & $0.296^{* * *}$ & -0.034 & $0.218^{* * *}$ & & & & & \\
\hline $\mathrm{Mg}^{2+}$ & 0.040 & $0.251^{\text {** }}$ & $0.283^{* * *}$ & -0.148 & 0.123 & & & & \\
\hline DOC & -0.070 & -0.039 & 0.129 & 0.062 & $0.376^{* *}$ & 0.098 & & & \\
\hline AI & 0.001 & -0.107 & -0.244 & 0.017 & -0.113 & -0.024 & -0.284 & & \\
\hline EC & $0.590^{* * *}$ & $0.855^{* * *}$ & -0.043 & $0.336^{* * *}$ & $0.333^{* *}$ & $0.305^{* *}$ & -0.005 & -0.219 & \\
\hline Eh & $0.365^{* *}$ & $0.442^{* * *}$ & -0.486 & $0.451^{* * *}$ & -0.105 & -0.016 & -0.291 & -0.003 & $0.293^{* *}$ \\
\hline
\end{tabular}

表 2 B 层土壤溶液各指标 Person 相关分析 $r$ 值

Table 2 Person correlation Analysis of Various Indicators in soil solution of layer B

\begin{tabular}{|c|c|c|c|c|c|c|c|c|c|}
\hline $\begin{array}{l}\text { 指标 } \\
\text { Indicators }\end{array}$ & $\mathrm{NH}_{4}^{+}$ & $\mathrm{NO}_{3}^{-}$ & $\mathrm{pH}$ & $\mathrm{Al}^{3+}$ & $\mathrm{Ca}^{2+}$ & $\mathrm{Mg}^{2+}$ & DOC & AI & $\mathrm{EC}$ \\
\hline $\mathrm{NO}_{3}^{-}$ & $0.385^{* *}$ & & & & & & & & \\
\hline $\mathrm{pH}$ & -0.266 & -0.335 & & & & & & & \\
\hline $\mathrm{Al}^{3+}$ & $0.330^{* *}$ & $0.485^{\text {*** }}$ & -0.154 & & & & & & \\
\hline $\mathrm{Ca}^{2+}$ & 0.011 & $0.183 *$ & 0.088 & $0.314^{\text {** }}$ & & & & & \\
\hline $\mathrm{Mg}^{2+}$ & -0.064 & 0.248 ** & $0.180 *$ & -0.121 & -0.006 & & & & \\
\hline DOC & -0.002 & -0.025 & 0.102 & $0.313^{* * *}$ & $0.524^{\text {** }}$ & 0.101 & & & \\
\hline AI & -0.029 & 0.090 & -0.331 & 0.068 & -0.147 & -0.109 & -0.188 & & \\
\hline EC & $0.358^{* *}$ & $0.855^{\text {** }}$ & -0.072 & $0.370^{\text {*** }}$ & 0.150 & $0.327^{* * *}$ & -0.107 & -0.177 & \\
\hline Eh & $0.267^{* *}$ & $0.481^{\text {** }}$ & -0.612 & $0.533^{* * *}$ & -0.004 & -0.064 & -0.203 & 0.002 & $0.361^{* *}$ \\
\hline
\end{tabular}

\section{3 讨论}

\section{1 该生态系统的 $\mathrm{N}$ 素状态和响应}

本研究中, 自然状态下, 两个深度土壤溶液 $\mathrm{NO}_{3}^{-}$占无机 $\mathrm{N}$ 的摩尔比均高于 $90 \%$, 而前期对该样地的研究 显示, $0-20 \mathrm{~cm}$ 土壤硝态 $\mathrm{N}$ 占无机 $\mathrm{N}$ 的比例约为 $60 \%{ }^{[16]}$ 。这表明在该生态系统中,不管是土壤胶体表面还 
是土壤溶液中, 均以硝态 $\mathrm{N}$ 占主导; $\mathrm{B}$ 层土壤溶液中 $\mathrm{NO}_{3}^{-}$达 $4.27 \mathrm{mg} / \mathrm{L}$, 这一数值远高于欧洲 100 个观测样点 中针叶林和阔叶林土壤溶液硝酸盐平均值 (分别为 1.5 和 $2.6 \mathrm{mg} / \mathrm{L})^{[32]}$ 。由于在大多数土壤中, 土壤胶体总 体带负电荷, 导致土壤中硝态 $\mathrm{N}$ 的移动性极强, 但与此同时, 土壤溶液中的无机 $\mathrm{N}$ 也可被植物和微生物迅速 利用。一般来说, 在 $\mathrm{pH}$ 较低的极酸性土壤中, 土壤黏粒会带有一定量正电荷, 使得阴离子也很难流失。因 此, 在正常情况下本研究样地不会发生大量的阴离子淋溶。但本研究中, 下层土壤溶液中极高的硝态 $\mathrm{N}$ 含 量, 以及 $\mathrm{B}$ 层土壤溶液硝酸盐浓度显著高于 $\mathrm{A}$ 层浓度, 意味着有大量的 $\mathrm{NO}_{3}^{-}$淋溶出土体。硝态 $\mathrm{N}$ 的淋溶意 味着 $\mathrm{N}$ 的有效性超过植物和微生物总营养需求 ${ }^{[33]}$, 这一指标是判断生态系统是否 $\mathrm{N}$ 饱和的标志指标, 因此, 从结果来看,该亚热带常绿阔叶林生态系统已达到 $\mathrm{N}$ 饱和状态。

本研究的同一处理、同一土层的土壤溶液 $\mathrm{NO}_{3}^{-}$浓度 $(3.94-31.23 \mathrm{mg} / \mathrm{L})$ 明显高于 $\mathrm{NH}_{4}^{+}$浓度 $(0.05-1.15$ $\mathrm{mg} / \mathrm{L})$, 这与广东亚热带森林 ${ }^{[34]}$ 、东北阔叶混交林 ${ }^{[35]}$ 等研究结果一致, 即 $\mathrm{NO}_{3}^{-}$浓度至少比 $\mathrm{NH}_{4}^{+}$浓度高一个数 量级。这可能是硝化作用将未被同化的 $\mathrm{NH}_{4}^{+}$转化为 $\mathrm{NO}_{3}{ }^{-[36]}$, 这一过程直接导致 $\mathrm{NO}_{3}^{-}$浓度升高并造成土壤 $\mathrm{pH}$ 降低。本试验发现, $\mathrm{N}$ 添加对两个深度 $\mathrm{NO}_{3}^{-}$和 $\mathrm{NH}_{4}^{+}$浓度有显著增加作用, 进一步说明外源添加的无机 $\mathrm{N}$ 并未被同化, 因为这些 $\mathrm{N}$ 已远超过生物总营养需求。另外, $\mathrm{N}$ 添加导致的强硝化作用产生的酸性将促进黏粒 矿物晶格中的 $\mathrm{Al}^{3+}$ 活化, 并释放至土壤溶液中, 导致本研究中两个深度土壤溶液在土壤中 $\mathrm{Al}^{3+}$ 浓度激增。

\section{$3.2 \mathrm{~N}$ 添加对土壤酸碱平衡的影响}

硝化作用是土壤 $\mathrm{N}$ 转化的重要途径, 本研究中 $\mathrm{NO}_{3}^{-}$浓度远高于 $\mathrm{NH}_{4}^{+}$浓度, 说明该试验地土壤中发生了 大量的硝化作用, 硝化作用将 $\mathrm{NH}_{4}^{+}$转化为 $\mathrm{NO}_{3}^{-}$的过程中会产生大量的 $\mathrm{H}^{+}$, 当土壤中铝的主要存在形式一 铝硅酸盐吸收 $\mathrm{H}^{+}$超过一定值后, 矿物质中的铝活化, 释放出交换性 $\mathrm{Al}^{3+[14]}$; 随着致酸离子 $\mathrm{H}^{+}$与 $\mathrm{Al}^{3+}$ 活化并进 人土壤溶液、胶体表面,盐基离子在阳离子交换作用下将被致酸离子交换出来。另外, $\mathrm{N}$ 添加会显著提高土壤 溶液 $\mathrm{NO}_{3}^{-}$含量, 为维持溶液电荷平衡, 部分阳离子 (如 $\mathrm{Ca}^{2+} 、 \mathrm{Mg}^{2+}$ ) 从土壤固相进人土壤溶液 ${ }^{[37]}$, 本研究中 $\mathrm{Ca}^{2+} 、 \mathrm{Mg}^{2+}$ 浓度与 $\mathrm{NO}_{3}^{-}$浓度呈显著正相关也印证了这种说法。本研究中 $\mathrm{Ca}^{2+} 、 \mathrm{Mg}^{2+}$ 浓度随 $\mathrm{N}$ 添加增加而未达 到显著水平, 原因可能是在试验后期改施 $\mathrm{NaNO}_{3}$ 和 $\mathrm{NH}_{4} \mathrm{Cl}$, 外施的阳离子 $\mathrm{Na}^{+}$随着 $\mathrm{NO}_{3}^{-}$淋失, 而减弱了 $\mathrm{N}$ 添加 对 $\mathrm{Ca}^{2+} 、 \mathrm{Mg}^{2+}$ 的影响。结合课题组前期试验结果 $\mathrm{N}$ 添加显著减少土壤及植物根系的 $\mathrm{Mg}^{2+}$ 含量 ${ }^{[28,38]}, \mathrm{N}$ 沉降的 持续增加可能会使土壤盐基离子发生进一步淋失。

本研究中 $\mathrm{N}$ 添加显著提高 $\mathrm{Al}^{3+}$ 浓度, 这与元晓春 ${ }^{[39]}$ 等对亚热带杉木人工林土壤溶液的研究结果相似。 一般认为, 对土壤酸化的缓冲调节主要受土壤的金属离子影响, 土壤 $\mathrm{pH}$ 值不同, 缓冲其酸化的金属阳离子可 能也不同 ${ }^{[13]}$ 。在 $\mathrm{pH}$ 为 4.5 到 7.5 时,酸化更多地由盐基离子来缓冲, 当盐基离子用尽时, 将由非盐基离子调 控缓冲, 这 (主要是 $\mathrm{Al}^{3+}$ ) 将对植物产生潜在的危害 ${ }^{[13]}$ 。本试验中 $\mathrm{HN}$ 处理对 $\mathrm{Al}^{3+}$ 浓度的影响, 反映出该试验 地土壤很可能已经转移到 $\mathrm{Al}^{3+}$ 缓冲土壤酸化的阶段; 此外, $\mathrm{Al}^{3+}$ 浓度增加会抑制根系吸收阳离子, 从而影响树 木根系生长以及代谢功能 ${ }^{[40]}$ 。土壤溶液 $\mathrm{pH}$ 值及 $\mathrm{Al}^{3+}$ 浓度对 $\mathrm{HN}$ 处理的响应, 反映了 $\mathrm{N}$ 饱和时 $\mathrm{N}$ 添加会使土 壤溶液持续酸化。

\section{$3.3 \mathrm{~N}$ 添加对土壤溶液可溶性有机碳的影响}

本研究中, $N$ 添加显著抑制土壤溶液 DOC 浓度, 这与福建杉木人工林 ${ }^{[24,39]}$ 、东北阔叶混交林 ${ }^{[35]}$ 的研究结 果一致。调落物, 尤其是调落叶, 是森林 $\mathrm{C}$ 输人的主要来源, 而 DOC 是调落物分解过程的产物之一。本课题 组对该试验地的研究发现, $\mathrm{N}$ 添加对本试验地调落物输人量并未产生显著影响 ${ }^{[17]}$ 而显著抑制了调落物的分 解 ${ }^{[41]}$, 因此调落物输人量并不是引起试验地 DOC 浓度变化的原因, 而调落物分解的速率改变可能是主要因 素。木质素是调落物分解后期的关键成分 ${ }^{[42]}, \mathrm{N}$ 添加会改变分解环境, 如降低 $\mathrm{pH}$ 值、增加可交换性金属离子 等, 从而抑制木质素分解微生物种类的活性, 以及抑制木聚糖酶和过氧化物酶的活性从而抑制木质素的分 解 ${ }^{[43]}$, 导致 DOC 减少。其次, 本试验中 $\mathrm{N}$ 添加使 $\mathrm{Al}^{3+}$ 活化, 而释放的 $\mathrm{Al}^{3+}$ 可与土壤有机分子络合, 形成稳定 不易分解的化合物而留在土壤固相中, 即土壤溶液 DOC 浓度降低 ${ }^{[44]} \mathrm{N}$ 添加也可能使植物的细根生物量降 低,从而降低由根系分解及根系分泌物产生的 DOC。 
芳香腐殖质是指土壤溶液中溶解性有机质 (DOM) 内比较稳定、不易被微生物分解的分子。AI 是评价 DOM 中芳香结构含量的重要指标, AI 值越高, 表明 DOM 中芳香化合物相对含量越高, 即 DOM 结构越复 杂 ${ }^{[24]}$ 。本试验的 $\mathrm{AI}$ 值普遍不高, 与元晓春等 ${ }^{[39]}$ 对福建杉木人工林的试验结果相似, 说明 DOM 中芳香化合 物所占比例低,结构简单。本试验中, A 层 AI 值随 $\mathrm{N}$ 添加的增加而增加, B 层 $\mathrm{AI}$ 值则无影响。元晓春等 ${ }^{[24]}$ 对福建杉木人工林的研究发现 0-15 $\mathrm{cm}$ 时 $\mathrm{N}$ 添加显著影响 DOM 结构, $30 \mathrm{~cm}$ 时 $\mathrm{N}$ 添加对 DOM 结构无影响, 表明土层越深, 有机质结构受 $\mathrm{N}$ 添加的影响逐渐减小。这可能由微生物活动造成, 土层越深, 土壤中微生物 活动越弱, 因此 DOM 结构在土壤下层未发生显著变化。

$3.4 \mathrm{~N}$ 添加对土壤溶液 $\mathrm{EC} 、 \mathrm{Eh}$ 的影响

$\mathrm{EC}$ 是物质导电的性能, 与溶液所含离子种类和数量相关,一般用来表示离子强度 ${ }^{[21]}$ 。本研究中 $\mathrm{EC}$ 与 $\mathrm{NO}_{3}^{-} 、 \mathrm{Al}^{3+} 、 \mathrm{NH}_{4}^{+} 、 \mathrm{Mg}^{2+}$ 等均呈显著正相关, 特别是与 $\mathrm{NO}_{3}^{-}$的相关系数达到 0.855 , 表明硝酸盐在维持土壤溶液的 电荷平衡过程中起着重要作用。 $\mathrm{N}$ 添加显著提高土壤溶液 $\mathrm{NO}_{3}^{-}$浓度, 增大了溶液负电荷密度, 对 $\mathrm{Al}^{3+} 、 \mathrm{Mg}^{2+}$ 等 阳离子的引力增加 ${ }^{21]}$, 带正电荷的阳离子增加导致土壤溶液 $\mathrm{EC}$ 显著升高。因此, 硝酸盐浓度的显著增加是 本研究 $\mathrm{EC}$ 增大的最直接原因。 EC 随 $\mathrm{N}$ 添加量的增加而升高, 表明 $\mathrm{N}$ 添加提高了土壤溶液的盐含量。通常 来说, 盐含量一定程度的升高可为植物生长提供充足的养分, 然而 EC 过高则可能对植物产生胁迫。

$\mathrm{Eh}$ 是土壤溶液中多种氧化及还原物质进行各种反应后的综合体现, 能够反映土壤溶液氧化还原性质的 相对程度, 也是影响重金属活性的关键因子 ${ }^{[45]}$ 。本研究中, CK 下, 两层土壤溶液 $\mathrm{Eh}$ 分别为 $249 \mathrm{mV}$ (A 层) 和 $276 \mathrm{mV}$ (B 层), $\mathrm{N}$ 添加使 $\mathrm{Eh}$ 显著升高, 即氧化性增强, 从而促进土壤形成铁锰氧化物, 铁锰氧化物会吸附某 些重金属离子, 导致这部分重金属离子在土壤中迁移率降低 ${ }^{[45]}$ 。

\section{4 结论}

本研究说明该试验地已达到氮饱和状态, 且该状态下土壤溶液酸化及铝活化仍在持续; $\mathrm{N}$ 添加下土壤溶 液氧化性增强,从而使某些重金属离子迁移率降低。

\section{参考文献 (References) :}

[ 1 ] Zhang W F, Dou Z X, He P, Ju X T, Powlson D, Chadwick D, Norse D, Lu Y L, Zhang Y, Wu L, Chen X P, Cassman K G, Zhang F S. New technologies reduce greenhouse gas emissions from nitrogenous fertilizer in China. Proceedings of the National Academy of Sciences of the United States of America, 2013, 110(21): 8375-8380.

[ 2 ] Galloway J N, Dentener F J, Capone D G, Boyer E W, Howarth R W, Seitzinger S P, Asner G P, Cleveland C C, Green P A, Holland E A, Karl D M, Michaels A F, Porter J H, Townsend A R, Vörösmarty C J. Nitrogen cycles: past, present, and future. Biogeochemistry, 2004, 70( 2) : 153-226.

[ 3 ] Canfield D E, Glazer A N, Falkowski P G. The evolution and future of Earth's nitrogen cycle. Science, 2010, 330( 6001): $192-196$.

[ 4 ] Liu X J, Zhang Y, Han W X, Tang A H, Shen J L, Cui Z L, Vitousek P, Erisman J W, Goulding K, Christie P, Fangmeier A, Zhang F S. Enhanced nitrogen deposition over China. Nature, 2013, 494(7438): 459-462.

[ 5 ] 赵晶, 间文德, 郑威, 李忠文. 樟树人工林调落物养分含量及归还量对氮沉降的响应. 生态学报, 2016, 36(2): 350-359.

[ 6 ] de Souza J C, Pereira M A, da Costa E N D, da Silva D M L. Nitrogen dynamics in soil solution under different land uses: Atlantic forest and cacao-cabruca system. Agroforestry Systems, 2018, 92(2): 425-435.

[ 7 ] 宋静, 骆永明, 赵其国. 土壤溶液采样技术进展. 土壤, 2000, 32(2): 102-106.

[8] 苏春田, 唐健生, 潘晓东, 邹胜章. 黎塘岩溶区铁锰结核胁迫下土壤溶液的化学特征分析. 湖北农业科学, 2014, 53(7): 1531-1534.

[9] 葛晓改, 曾立雄, 肖文发, 黄志霖, 周本智. 模拟 $\mathrm{N}$ 沉降下不同林龄马尾松林凋落叶分解-土壤 $\mathrm{C} 、 \mathrm{~N}$ 化学计量特征. 生态学报, 2017,37 (4) : 1147-1158.

[10] 李素新, 覃志杰, 刘泰瑞, 郭晋平. 模拟氮沉降对华北落叶松人工林土壤微生物碳和微生物氮的动态影响. 水土保持学报, 2020, 34(1): 268-274.

[11] 陈美领, 陈浩, 毛庆功, 朱晓敏, 莫江明. 氮沉降对森林土壤磷循环的影响. 生态学报, 2016, 36(16): 4965-4976.

[12] 陈雨芩, 陈冠陶, 梁政, 李仁洪, 马豪宇, 涂利华. 10 年氮添加未显著影响苦竹林土壤磷组分. 生态环境学报, 2018, 27 (4) : 677-684.

[13] Tian D S, Niu S L. A global analysis of soil acidification caused by nitrogen addition. Environmental Research Letters, 2015,10 (2): 024019.

[14] Chen G T, Tu L H, Chen G S, Hu J Y, Han Z L. Effect of six years of nitrogen additions on soil chemistry in a subtropical Pleioblastus amarus forest, Southwest China. Journal of Forestry Research, 2018, 29(6): 1657-1664.

[15] 涂利华, 胡红玲, 胡庭兴, 张健, 肖银龙, 雒守华, 李仁洪, 戴洪忠. 模拟氮沉降对华西雨屏区光皮桦林土壤酶活性的影响. 应用生态学 报, 2012, 23(8): 2129-2134.

[16] 孙宇, 彭天驰, 李顺, 周培, 王婷, 钱学诗, 刘采鹏, 陈雨芩, 马豪宇, 李曾燕, 涂利华. 模拟氮沉降对湿性常绿阔叶次生林土壤碳氮组 
分和酶活性的影响. 水土保持学报, 2019, 33(2): 235-243, 250-250.

[17］李顺. 施氮和调落物增减对湿性常绿阔叶林土壤呼吸和土壤碳、氮的影响 [D ]. 成都: 四川农业大学, 2018.

[18] Giesler R, Lundström U S, Grip H. Comparison of soil solution chemistry assessment using zero-tension lysimeters or centrifugation. European Journal of Soil Science, 1996, 47(3): 395-405.

[19] Iost S, Rautio P, Lindroos A J. Spatio-temporal trends in soil solution $\mathrm{Bc} / \mathrm{Al}$ and $\mathrm{N}$ in relation to critical limits in European forest soils. Water, Air, \& Soil Pollution, 2012, 223(4) : 1467-1479.

[20] Mitchell A D, Smethurst P J. Base cation availability and leaching after nitrogen fertilisation of a eucalypt plantation. Australian Journal of Soil Research, 2008, 46(5): 445-454.

[21] Sanderson T M, Barton C, Cotton C, Karathanasis T. Long-term evaluation of acidic atmospheric deposition on soils and soil solution chemistry in the Daniel Boone National forest, USA. Water, Air, \& Soil Pollution, 2017, 228(10) : 403.

[22] Camino-Serrano M, Gielen B, Luyssaert S, Ciais P, Vicca S, Guenet B, De Vos B, Cools N, Ahrens B, Arain M A, Borken W, Clarke N, Clarkson B, Cummins T, Don A, Pannatier E G, Laudon H, Moore T, Nieminen T M, Nilsson M B, Peichl M, Schwendenmann L, Siemens J, Janssens I. Linking variability in soil solution dissolved organic carbon to climate, soil type, and vegetation type. Global Biogeochemical Cycles, 2014, 28(5): 497-509.

[23 ] Camino-Serrano M, Pannatier E G, Vicca S, Luyssaert S, Jonard M, Ciais P, Guenet B, Gielen B, Peñuelas J, Sardans J, Waldner P, Etzold S, Cecchini G, Clarke N, Galić Z, Gandois L, Hansen K, Johnson J, Klinck U, Lachmanová Z, Lindroos A J, Meesenburg H, Nieminen T M, Sanders T G M, Sawicka K, Seidling W, Thimonier A, Vanguelova E, Verstraeten A, Vesterdal L, Janssens I A. Trends in soil solution dissolved organic carbon (DOC) concentrations across European forests. Biogeosciences, 2016, 13(19): 5567-5585.

[24] 元晓春, 陈岳民, 袁硕, 郑蔚, 司友涛, 元志鹏, 林伟盛, 杨玉盛. 氮沉降对杉木人工幼林土壤溶液可溶性有机物质浓度及光谱学特征的 影响. 应用生态学报, 2017, 28(1): 1- 11.

[25] Xu X K, Han L, Luo X B, Liu Z R, Han S J. Effects of nitrogen addition on dissolved $\mathrm{N}_{2} \mathrm{O}$ and $\mathrm{CO}_{2}$, dissolved organic matter, and inorganic nitrogen in soil solution under a temperate old-growth forest. Geoderma, 2009, 151(3/4): 370-377.

[26] 姜杰, 杨浈, 任谦, 孙国新. 土壤腐殖质氧化还原电位及其相应电子转移能力分布. 环境化学, 2015, 34(2): 219-224.

[27] Xu Z F, Tu L H, Hu T X, Schädler M. Implications of greater than average increases in nitrogen deposition on the western edge of the Szechwan Basin, China. Environmental Pollution, 2013, 177: 201-202.

[28］彭天驰. 模拟氮沉降对次生湿性常绿阔叶林土壤生化特性的影响 [D]. 成都: 四川农业大学, 2018.

[29] Peng Y, Song S Y, Li Z Y, Li S, Chen G T, Hu H L, Xie J L, Chen G, Xiao Y L, Liu L, Tang Y, Tu L H. Influences of nitrogen addition and aboveground litter-input manipulations on soil respiration and biochemical properties in a subtropical forest. Soil Biology and Biochemistry, 2020, 142: 107694 .

[30］马豪宇. 模拟氮沉降对湿性常绿阔叶林土壤溶液化学特性的影响 [D]. 成都: 四川农业大学, 2019.

[31] Weishaar J L, Aiken G R, Bergamaschi B A, Fram M S, Fujii R, Mopper K. Evaluation of specific ultraviolet absorbance as an indicator of the chemical composition and reactivity of dissolved organic carbon. Environmental Science \& Technology, 2003, 37(20) : 4702-4708.

[32] Kristensen H L, Gundersen P, Callesen I, Reinds G J. Throughfall nitrogen deposition has different impacts on soil solution nitrate concentration in European coniferous and deciduous forests. Ecosystems, 2004, 7(2): 180- 192.

[33] Aber J D, Magill A, Boone R, Melillo J M, Steudler P. Plant and soil responses to chronic nitrogen additions at the Harvard forest, Massachusetts. Ecological Applications, 1993, 3(1): 156- 166.

[34] Fang Y T, Zhu W X, Gundersen P, Mo J M, Zhou G Y, Yoh M. Large loss of dissolved organic nitrogen from nitrogen-saturated forests in subtropical China. Ecosystems, 2009, 12(1): 33-45.

[35] Xu X K, Luo X B, Han L, Cao F Q, Han S J. Effects of nitrogen addition on fluxes and concentrations of dissolved organic matter and inorganic nitrogen under a temperate old-growth forest in northeast China//2010 19th World Congress of Soil Science, Soil Solutions for a Changing World. Brisbane, Australia: International Union of Soil Sciences (IUSS), c/o Institut für Bodenforschung, Universität für Bodenkultur, 2010, $131-134$.

[36] Moore J D, Houle D. Soil solution and sugar maple response to $\mathrm{NH}_{4} \mathrm{NO}_{3}$ additions in a base-poor northern hardwood forest of Québec, Canada. Environmental Monitoring and Assessment, 2009, 155(1/4): 177-190.

[37] Pannatier E G, Thimonier A, Schmitt M, Walthert L, Waldner P. A decade of monitoring at Swiss Long-Term Forest Ecosystem Research (LWF) sites: can we observe trends in atmospheric acid deposition and in soil solution acidity? Environmental Monitoring and Assessment, 2011, 174(1/ 4) : 3-30.

[38] 陈冠陶, 郑军, 彭天驰, 李顺, 邱细容, 陈雨芩, 马豪宇, 涂利华. 扁刺栲不同根序细根形态和化学特征及其对短期氮添加的响应. 应用 生态学报, 2017, 28(11): 3461-3468.

[39］元晓春, 杨景清, 王铮, 袁硕, 杨舟然, 陈岳民, 杨玉盛. 增温和施氮对亚热带杉木人工林土壤溶液养分的影响. 生态学报, 2018, 38 (7) : 2323-2332

[40] Chen G T, Tu L H, Peng Y, Hu H L, Hu T X, Xu Z F, Liu L, Tang Y. Effect of nitrogen additions on root morphology and chemistry in a subtropical bamboo forest. Plant and Soil, 2017, 412(1/2): 441-451.

[41］李曾燕. 氮添加和调落物增减对亚热带常绿阔叶林凋落叶分解的影响 [D ]. 成都: 四川农业大学, 2020.

[42] Jiang X Y, Cao L X, Zhang R D, Yan L J, Mao Y, Yang Y W. Effects of nitrogen addition and litter properties on litter decomposition and enzyme activities of individual fungi. Applied Soil Ecology, 2014, 80: 108-115.

[43] Zhang X, Liu Z. Responses of litter decomposition and nutrient release of Bothriochloa ischaemum to soil petroleum contamination and nitrogen fertilization. International Journal of Environmental Science and Technology, 2019, 16(2): 719-728.

[44] Zia A, van den Berg L, Ahmad M N, Riaz M, Zia D, Ashmore M. Controls on accumulation and soil solution partitioning of heavy metals across upland sites in United Kingdom (UK). Journal of Environmental Management, 2018, 222: 260-267.

[45] 毛凌晨, 叶华. 氧化还原电位对土壤中重金属环境行为的影响研究进展. 环境科学研究, 2018, 31(10): 1669-1676. 